\title{
Novel Dispersion of 1D Nanofiber Fillers for Fast Ion-Conducting Nanocomposite Polymer Blend Quasi-solid Electrolytes for Dye- Sensitized Solar Cells
}

\author{
Vinoth Subramanian ${ }^{a}$, Kamatam Hari Prasad $^{b}$, Himadri Tanaya Das $^{c}$, Kanimozhi Ganapathy $^{d}$, \\ Satyanarayana Nallani ${ }^{d}{ }^{*}$ Thandavarayan Maiyalagan ${ }^{e}$ \\ a Department of ECE, ManakulaVinayagar Institute of Technology, \\ Puducherry, 605014,India. \\ ${ }^{\mathrm{b}}$ Department of Physics, Institute of Aeronautical Engineering, Hyderabad, 500043,India. \\ ${ }^{c}$ Centre of Advanced Materials and Applications, Utkal University, \\ Vanivihar, Bhubaneswar, Odisha, 751004, India. \\ ${ }^{\mathrm{d} D e p a r t m e n t}$ of Physics, Pondicherry University, Puducherry, 605014, India. \\ e Department of Chemistry, SRM institute of Science and Technology, \\ Tamilnadu, 603203, India. \\ Email address: nallanis2011@gmail.com (N. Satyanarayana), \\ maiyalagan@gmail.com (T. Maiyalagan)
}

\section{Supporting information}


Supplementary data S1: Figure S1 (a), shows the electrolyte uptake of the of electro spun blended polymeric nanocomposite membranes of PVDF-HFP-PMMA $x$ wt $\%$ of $\mathrm{TiO}_{2} \mathrm{NFs}(x=0,2,4,6,8)$ with distinct iodide-triiodide redox agents based on cations $\mathrm{Li}, \mathrm{Na}, \mathrm{K}$, TBA. It was observed that the PVDFHFP-PMMA membrane of $6 \mathrm{wt} \% \mathrm{TiO}_{2}$ nanofiber fillers with LiI redox couple shows a highest uptake of $\sim 480 \%$. Figure S1 (b) and its variation is similar to electrolyte uptake behavior as observed in figure S1

a.
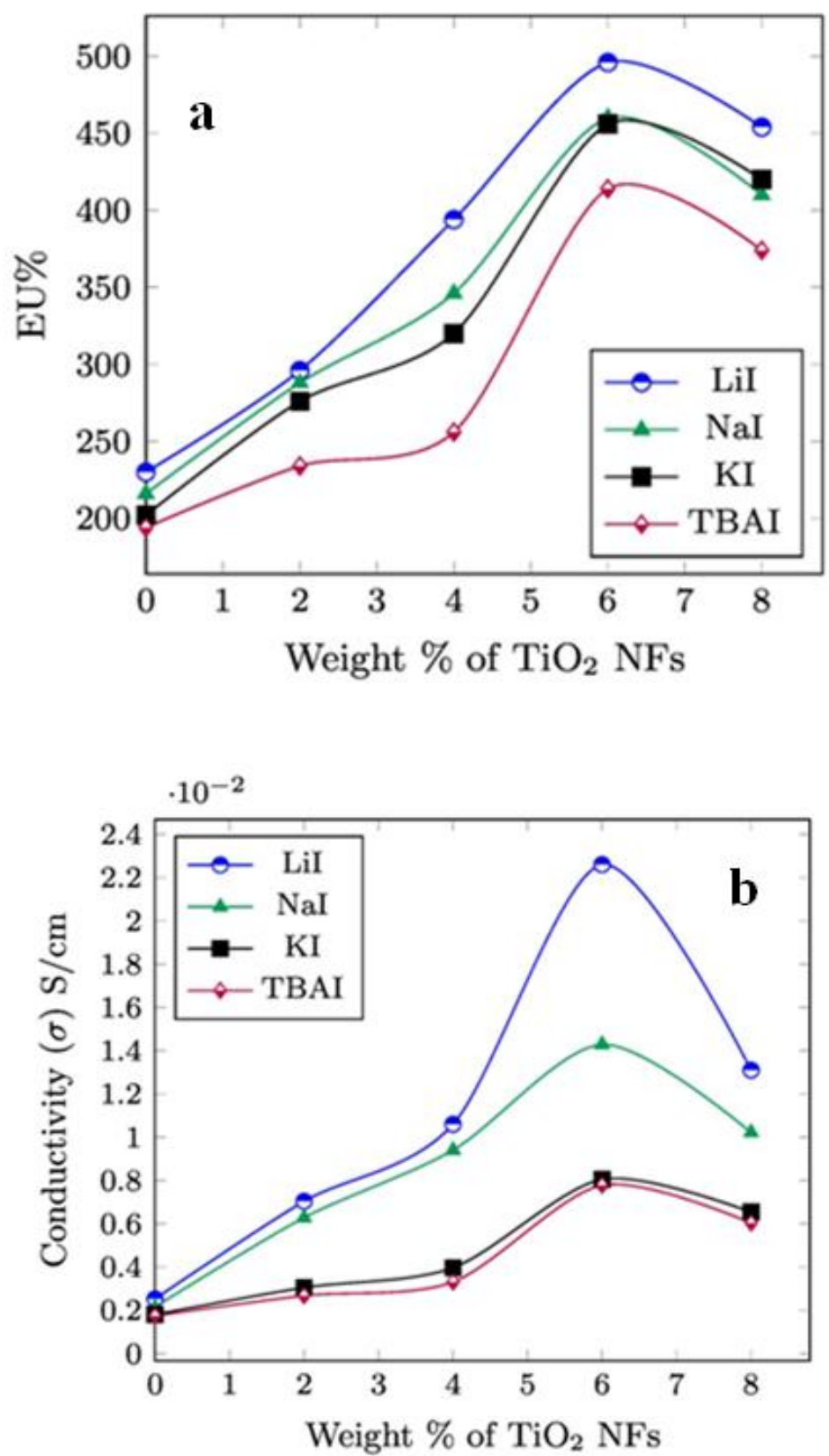

Figure S1: a.) Electrolyte uptake and b.) Variation in conductivity of electro spun blended polymeric nanocomposite membranes of PVDF-HFP-PMMA $x$ wt $\%$ of $\mathrm{TiO}_{2}$ NFs $(x=0,2,4,6,8)$ with distinct iodide-triiodide redox agents based on cations $\mathrm{Li}, \mathrm{Na}, \mathrm{K}, \mathrm{TBA}$. 
Supplementary data S2: Figure S2, shows the conductivity spectra of electro spun blended polymeric nanocomposite membranes of PVDF-HFP-PMMA/ $x$ wt $\%$ of $\mathrm{TiO}_{2} \quad \mathrm{NFs} \quad(x=0,2,4,6,8)$ withdistinctiodidetriiodideredoxagents (a) $\mathrm{LiI} / \mathrm{I}_{2}$ (b) $\mathrm{NaI} / \mathrm{I}_{2}$ (c) $\mathrm{KI} / \mathrm{I}_{2}$ and (d) $\mathrm{TBAI} / \mathrm{I}_{2}$. From figure $\mathrm{S} 2$, It was noted that the conductivity spectra curve raises with the increase in the weight $\%$ of fillers up to an optimum concentration of $6 \mathrm{wt} \%$ and then lowers at $8 \mathrm{wt} \%$.

(a) LiI
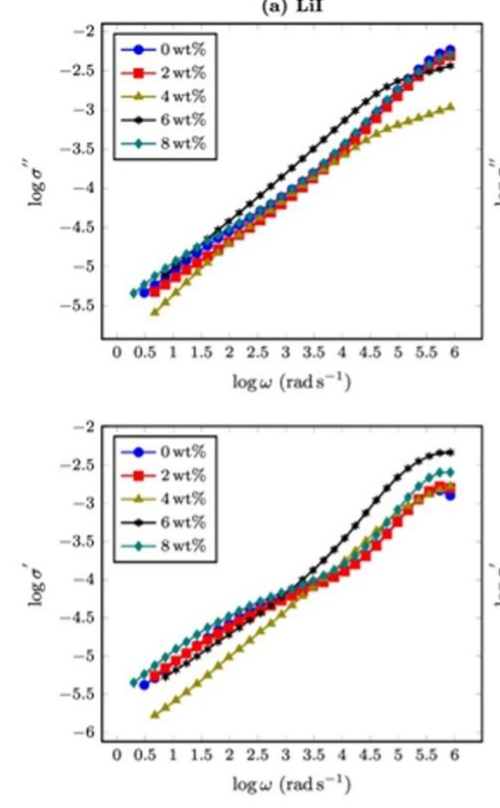

(c) KI
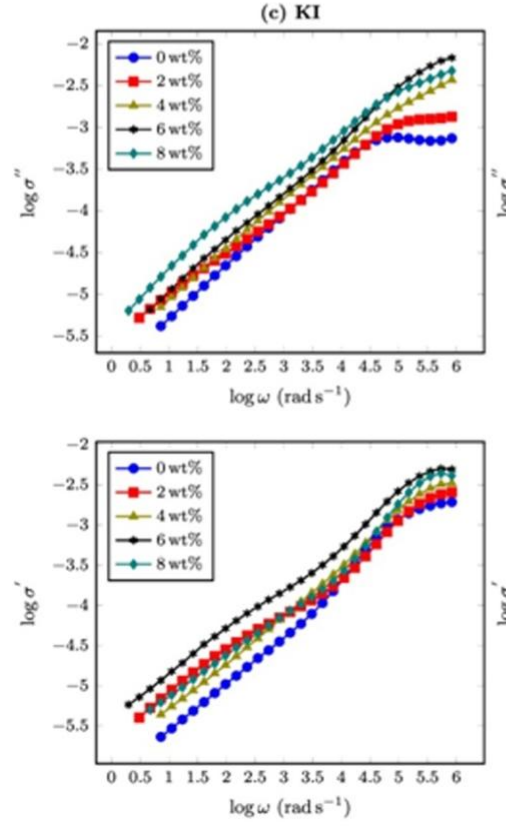

(b) NaI

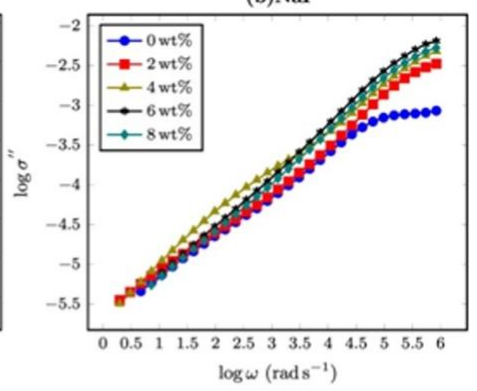

$\log \omega\left(\mathrm{rads}^{-1}\right)$

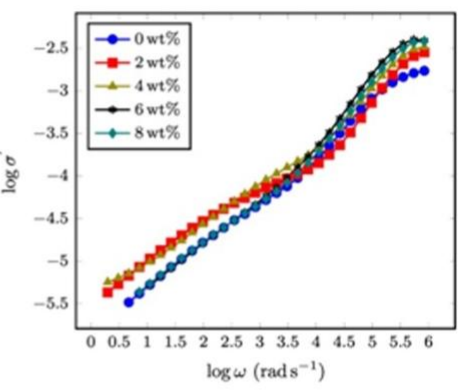

(d) TBAI
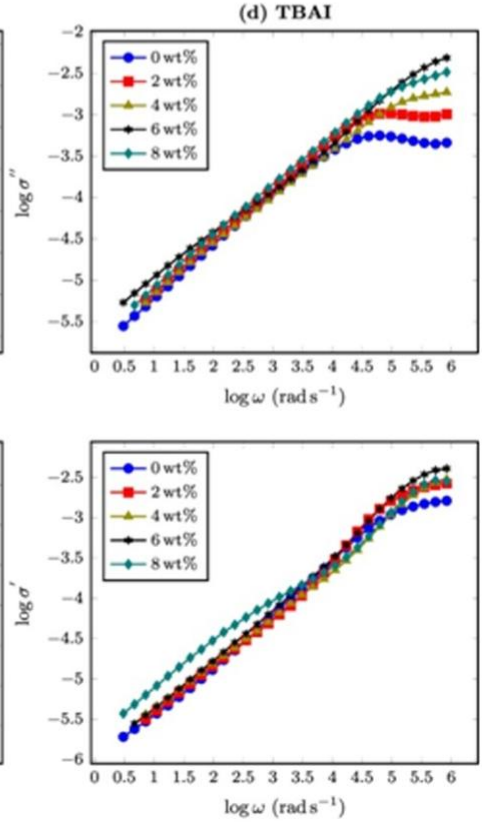

Figure S2: Conductivity spectra of electro spun blended polymeric nano-composite membranes of PVDF-HFPPMMA $x$ wt $\%$ of $\mathrm{TiO}_{2} \mathrm{NFs}\left(x=0,2,4,6,8\right.$ ) with distinct iodide-triiodide redox agents (a) $\mathrm{LiI} / \mathrm{I}_{2}$ (b) $\mathrm{NaI} / \mathrm{I}_{2}$ (c) $\mathrm{KI} / \mathrm{I}_{2}$ and (d) $\mathrm{TBAI} / \mathrm{I}_{2}$ 
Supplementary data S3: Figure S3, shows the dielectric spectra of electro spun blended polymeric nanocomposite membranes of PVDF-HFP-PMMA/ $x w t \%$ of $\mathrm{TiO}_{2} \mathrm{NFs}(x=0,2,4,6,8)$ with distinct iodide-triiodide redox agents (a) $\mathrm{LiI} / \mathrm{I}_{2}$ (b) $\mathrm{NaI} / \mathrm{I}_{2}$ (c) $\mathrm{KI} / \mathrm{I}_{2}$ and (d) $\mathrm{TBAI} / \mathrm{I}_{2}$. The dielectric strength of the developed electro spun blended polymeric nanocomposite electrolytes PVDF-HFP-PMMA with $\mathrm{TiO}_{2} \mathrm{NFs}$ varies in accordance with the presence of the iodide-triiodide redox agents based on cations arranged in order as $\mathrm{Li}>\mathrm{Na}>\mathrm{K}>\mathrm{TBA}$. Obviously, $\mathrm{Li}$ based PVDF-HFP-PMMA with $6 \mathrm{wt} \% \mathrm{TiO}_{2} \mathrm{NFs}$ electrolyte has highest $\delta$. The observed inference very well supports the complex conductivity analysis.
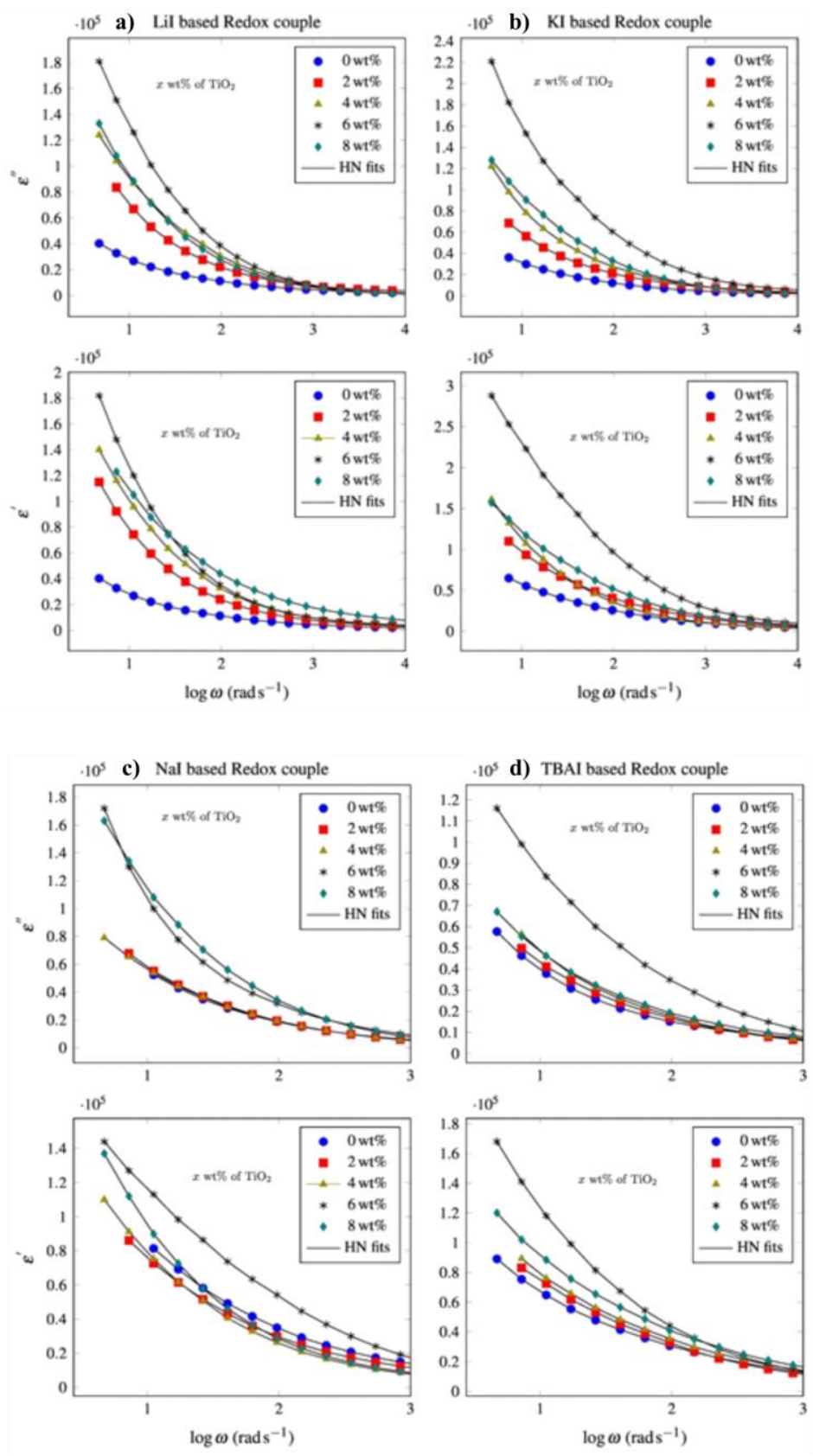

Figure S3: Dielectric spectra of electro spun blended polymeric nano- composite membranes of PVDF-HFPPMMA $x w t \%$ of $\mathrm{TiO}_{2} \mathrm{NFs}(x=0,2,4,6,8)$ with distinct iodide-triiodide redox agents (a) $\mathrm{LiI} / \mathrm{I}_{2}$ (b) $\mathrm{NaI} / \mathrm{I}_{2}$ (c) $\mathrm{KI} / \mathrm{I}_{2}$ and (d) $\mathrm{TBAI} / \mathrm{I}_{2}$. 